\title{
Factors affecting the production of potential transgenic pigs by DNA microinjection; a six-year retrospective study
}

\author{
J. Jura' ${ }^{1}$ Z. Smorąg ${ }^{1,3}$, R. Słomski ${ }^{2}$, D. Lipiński ${ }^{2}$ and B. Gajda ${ }^{1}$ \\ ${ }^{I}$ National Research Institute of Animal Production \\ 32-083 Balice, Poland \\ ${ }^{2}$ The August Cieszkowski Agricultural University, Department of Biochemistry and Biotechnology \\ Wotyńska 35, 60-637 Poznań, Poland
}

(Received 12 July 2007; revised version 29 October 2007; accepted 21 November 2007)

\begin{abstract}
Transgenesis is a complex process. Among the most important factors affecting the production of potential transgenic pigs using standard DNA microinjection into zygote pronuclei are the type of promoter used to express the gene construct and the method of zygote transfer used for transformation. The transformation of zygotes using different gene constructs showed that the promoter type influenced the developmental capability of the transformed zygotes, and this affected the percentage of born piglets. The transfer of transformed zygotes into a single oviduct resulted in a higher percentage of potential transgenic piglets born, this figure was almost doubled compared with transfer into both oviducts. Recently, research into the production of transgenic pigs has shown that factors connected with reproduction physiology and embryological factors such as the number of zygotes transferred after transformation and the season of the year have a significant influence but are not critical to the efficiency of production of transgenic pigs. The best results were obtained when less than 20 transformed zygotes per recipient were transplanted and the autumn season is the time when the environmental factors are optimal for production of potential transgenic pigs.
\end{abstract}

KEY WORDS: pig, transgenesis, DNA microinjection, efficiency

\section{INTRODUCTION}

The production of transgenic animals is a complex process. Despite the development of increasingly sophisticated technologies, the efficiency of the process remains disproportionately low compared to labour inputs and costs. In pigs,

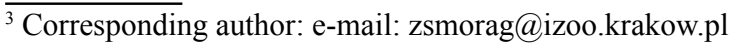


transgenic efficiency using standard DNA microinjection, which is still the leading technique in this species, does not exceed $2 \%$ in terms of the number of zygotes subjected to microinjection (Jura and Jurkiewicz, 2006).

Cloning techniques using transfected somatic cells or their nuclei to produce transgenic animals are even less efficient. The inefficiency of the cloning process is due to the complexity and limitations of the cloning procedure, which have been well documented in the previous literature (Jura and Jurkiewicz, 2006).

In the not distant future, it is hoped that application of lentiviral vectors, a new generation of DNA carriers, with promising transfection efficiency will dramatically improve the efficiency of production of transgenic animals, including pigs. However, this will only take place when researchers have developed commercially available vectors using safer types of lentiviruses, which will allow them to be used in laboratories with lower security levels (Jura and Jurkiewicz, 2006).

The gene constructs (vectors) used to carry genetic information to induce specific genotype modifications play a key role in the transgenesis process. The efficiency of this process affects the final success of the entire process.

Transgenesis is a very complex process and comprises many stages that may influence its efficiency. Other than molecular factors, embryological factors and physiological factors also affect the efficiency of trangenesis. One of the most important embryological factors is the quality of zygotes to be transformed and the effectiveness of the superovulation treatment which results in zygotes suitable for microinjection (Williams et al., 1992; Smorag et al., 1999).

Current studies on the production of transgenic pigs have shown that transfer procedures to the recipients, the number of transferred zygotes after transformation and the season of the year also have effects on the efficiency of transgenic pig production.

This paper presents data obtained over six years of research into the production of transgenic pigs using standard DNA microinjection techniques and is focused on analysis of embryological and physiological factors which influence efficiency of transgenesis in pigs.

\section{MATERIAL AND METHODS}

The research was performed on 6-8 month-old donor and recipient gilts (90-120 $\mathrm{kg} \mathrm{BW}$ ) of Polish Landrace, Duroc and synthetic line 990 and their crossbreeds.

\section{Collection of zygotes}

To obtain a sufficient number of zygotes suitable for DNA microinjection, donor gilts were superovulated by intramuscular injection of 1500 IU of PMSG (Serogonadotropin, Biowet, Poland), followed after $72 \mathrm{~h}$ by intramuscular injec- 
tion of 1000 IU of HCG (Biogonadyl, Biomed, Poland) (Holtz and Schlieper, 1991). After detection of oestrous signs ( $24 \mathrm{~h}$ after HCG administration), donor gilts were inseminated twice at $12 \mathrm{~h}$ intervals. Zygotes were recovered surgically or post-mortem by flushing oviducts with PBS containing $4 \%$ bovine albumin (Sigma, USA). The zygotes obtained were morphologically evaluated using a stereoscopic microscope. Zygotes with morphologically normal cytoplasm and two visible polar bodies were used for DNA microinjection.

\section{DNA microinjection}

Prior to DNA microinjection, morphologically normal zygotes were centrifuged to visualize the pronuclei $(15000 \mathrm{~g}, 5 \mathrm{~min})$ and placed in a micromanipulation chamber filled with PBS containing $20 \%$ foetal calf serum (FCS) (Sigma, USA). DNA microinjection was performed under an inverted microscope equipped with Nomarski's optics assisted by two micromanipulator units. The gene constructs were injected into one of the visualized pronuclei. After DNA microinjection, the transformed zygotes were transferred to a chamber containing albumin-supplemented solution and morphologically evaluated to eliminate any damaged zygotes. Only zygotes with an intact cytoplasmic structure were selected for transfer (Jura and Jurkiewicz, 2006).

The following 6 gene constructs were used for microinjection :

1. WAP-INF - expression gene construct - mammary gland specific Whey Acidic Protein promoter (WAP) linked to human interferon gene sequences (INF)

2. WAP-INF GFP - expression gene construct - as above, but containing a linked GFP reporter gene

3. pCMVCD59 - regulatory gene construct - human Cytomegalovirus promoter (systemic promoter) linked to human factor CD59 gene sequences

4. pCMVFut I - modifying gene construct - human Cytomegalovirus promoter (systemic promoter) linked to the human $\alpha 1,2$-fucosyltransferase enzyme with a short chain (FUT I)

5. pCMVFut II - modifying gene construct - human Cytomegalovirus promoter (systemic promoter) linked to the human $\alpha 1,2$-fucosyltransferase enzyme with a longer chain (FUT II)

6. pCMVCD46 - regulatory gene construct - human Cytomegalovirus promoter (systemic promoter) linked to human factor CD46 (membrane co-factor protein, MCP).

\section{Transfer of transformed zygotes}

After DNA microinjection, morphologically normal zygotes were surgically transferred into the oviducts of synchronized recipient gilts checked for signs of 
oestrous. Transplantation procedures were performed under full surgical anaesthesia. The oviducts were pulled out through a $2-3 \mathrm{~cm}$ long incision made in a white line. Transformed zygotes suspended in PBS supplemented with $20 \%$ FCS were expelled into the oviduct by insertion of a fine plastic canula connected to a Hamilton syringe. Two transfer methods were used:

1. transfer into both oviducts, where the pool of zygotes was equally divided between each of the oviducts

2. transfer into one oviduct.

The effectiveness of the transfer procedure was checked 56 days after transfer by ultrasonographic examination of the recipients. Pregnant sows were kept until parturition and the number of piglets was estimated.

\section{Evaluation of the results}

The results were analysed in terms of 4 groups of factors:

1. method of transfer of microinjected zygotes - transfer into a single oviduct vs transfer into two oviducts

2. type of gene constructs used

3. season of the year

4. number of transplanted zygotes (4 ranges):

I. $\leq 20$

II. $21-30$

III. $31-40$

IV. $\geq 40$

The efficiency of zygotes transfer after DNA microinjection was assessed based on the number of pregnant sows and the number of piglets born (live and stillborn).

\section{Statistical analysis}

Chi-square test was used to analyse the data presented in Tables 1-4.

\section{RESULTS}

The transformation of zygotes using different gene constructs showed that the promoter type influenced the developmental capability of the transformed zygotes, and this affected the percentage of born piglets. When the mammary-specific target promoter WAP was used, the percentage of piglets produced were higher in comparison to the percentage obtained when the gene construct with the pCMV 
promoter was used $(\mathrm{P}<0.01)$. The pCMV promoter acts as a strong systemic expression promoter of the introduced gene, and was also used for zygote transformation (Table 1). When different gene constructs using the same promoter were employed, the percentages of pregnancies were comparable but statistical analysis showed influence of a gene type on piglets productivity (Table 1).

Table 1. Results of transfer of DNA microinjected pig zygotes with different gene constructs into a single oviduct

\begin{tabular}{|c|c|c|c|c|c|c|}
\hline \multirow{3}{*}{ Gene construct } & \multirow{3}{*}{$\begin{array}{c}\text { Transferred } \\
\text { zygotes } \\
\text { n }\end{array}$} & \multirow{3}{*}{$\underset{\mathrm{n}}{\text { Recipients }}$} & \multirow{2}{*}{$\begin{array}{l}\text { Pregnant } \\
\text { recipients }\end{array}$} & \multicolumn{3}{|c|}{ Piglets born ${ }^{1}$} \\
\hline & & & & \multicolumn{2}{|r|}{ live } & \multirow{2}{*}{$\frac{\text { stillborn }}{\mathrm{n}}$} \\
\hline & & & n $\%$ & $\mathrm{n}$ & $\%$ & \\
\hline WAP-INF GFP & 371 & 12 & $8(66.6)$ & 42 & $(11.3)^{\mathrm{A}, \mathrm{C}, \mathrm{a}}$ & 5 \\
\hline pCMV CD59 & 2714 & 79 & $33(41.8)$ & 164 & $(6.0)^{\mathrm{B}}$ & 18 \\
\hline pCMV CD46 & 1893 & 67 & $27(40.3)$ & 151 & $(7.8)^{\mathrm{A}, \mathrm{C}, \mathrm{b}}$ & - \\
\hline pCMV FUT I & 551 & 26 & $10(38.5)$ & 48 & (8.7) & - \\
\hline pCMV FUT II & 1849 & 65 & $29(44.6)$ & 195 & $(10.5)^{\mathrm{D}}$ & 13 \\
\hline $\begin{array}{c}\text { pCMV FUT II + } \\
\text { pCMV CD46 }\end{array}$ & 518 & 15 & $6(40.0)$ & 40 & (7.7) & - \\
\hline
\end{tabular}

${ }^{1}$ percentage of piglets relative to the number of transferred zygotes. Different superscripts within a column indicate significant differences: ${ }^{\mathrm{A}, \mathrm{B}, \mathrm{C}, \mathrm{D}}-\mathrm{P}<0.01$ and ${ }^{\mathrm{a}, \mathrm{b}}-\mathrm{P}<0.05$

The transfer of transformed zygotes into a single oviduct resulted in a higher percentage of pregnant sows. In addition, introduction of this procedure resulted in a higher percentage of potential transgenic piglets born, this figure was almost doubled compared with transfer into both oviducts $(\mathrm{P}<0.01)$ (Table 2 ).

Table 2. Results of transfer of transformed porcine zygotes relative to the transfer method used - a single oviduct versus both oviducts

\begin{tabular}{lccccccc}
\hline \multirow{2}{*}{$\begin{array}{l}\text { Method of } \\
\text { deposition }\end{array}$} & $\begin{array}{c}\text { Transferred } \\
\text { zygotes }\end{array}$ & $\begin{array}{c}\text { Recipients } \\
\mathrm{n}\end{array}$ & \multicolumn{2}{c}{$\begin{array}{c}\text { Pregnant } \\
\text { recipients }\end{array}$} & & \multicolumn{3}{c}{ Piglets born $^{1}$} \\
\cline { 5 - 7 } & $\mathrm{n}$ & & $\mathrm{n} \%$ & & live & stillborn \\
\hline Single/one oviduct & 522 & 16 & $12(75.0)^{\mathrm{a}}$ & & $81(15.5)^{\mathrm{A}}$ & $\mathrm{n}$ \\
Two/both oviducts & 608 & 21 & $8(38.1)^{\mathrm{b}}$ & & 40 & $(6.6)^{\mathrm{B}}$ & - \\
\hline
\end{tabular}

${ }^{1}$ percentage of piglets relative to the number of transferred zygotes. Different superscripts within a column indicate significant differences: ${ }^{\mathrm{A}, \mathrm{B}}-\mathrm{P}<0.01$ and $^{\mathrm{a}, \mathrm{b}}-\mathrm{P}<0.05$

It is well known that manipulations such as in vitro culture or microinjection that are carried out on embryos at early developmental stages lower their developmental potential. During transgenesis, the process of DNA microinjection, where foreign information is mechanically inserted into one of the zygote pronuclei particularly reduces the developmental potential of the transformed zygotes. There- 
fore, the number of transformed zygotes transferred into the recipient oviduct has to be significantly large to maximize the chance of development. The procedure used aims to strengthen the implantation signal and increase the chance of normal foetus development after micromanipulation. In the case of pigs, a minimum number of 15 zygotes are transferred after microinjection into the oviducts of single recipient (Williams et al., 1992). There is no exact data about the upper limit for the number of zygotes or embryos that can be transferred. Data from the literature regarding cloning in pigs indicates that the number of transferred zygotes into one recipient can even be as high as several hundred zygotes (Kruip and Den Daas, 1997). Due to economic and purely practical reasons, it is important to determine the minimum and maximum number of transferred zygotes that enables the optimum number of potential transgenic offspring to be obtained during transgenesis. Our data (Table 3 ) showed that the percentage of pregnancies obtained was comparable in the range of 15-40 transformed zygotes per recipient, these are groups I, II and III in Table 3. The highest percentage of pregnant sows was obtained when more than 40 zygotes were transplanted (group IV), but in this group the percentage of obtained piglets was the lowest $(5.6 \%)$. The best results were obtained using the conditions for group $\mathrm{I}-12.4 \%$ of obtained piglets relative to the number of transferred zygotes $(\mathrm{P}<0.01)$. Comparable results were obtained in groups II and III (Table 3).

Table 3. Results of transfer of DNA microinjected pig zygotes (with different gene constructs) in comparison to the number of zygotes transferred into a single oviduct

\begin{tabular}{cccccccc}
\hline Group & $\begin{array}{c}\text { Transferred } \\
\text { zygotes per } \\
\text { recipient } \\
\mathrm{n}\end{array}$ & Recipients & $\begin{array}{c}\text { Total } \\
\text { transferred } \\
\text { zygotes }\end{array}$ & $\begin{array}{c}\text { Pregnant } \\
\text { sows }\end{array}$ & Piglets & $\begin{array}{c}\text { Mean piglets } \\
\text { per sow }\end{array}$ \\
\hline I & $\leq 20$ & 29 & 553 & $13(44.8)$ & $69(12.4)^{\mathrm{A}}$ & 5.3 \\
II & $21-30$ & 191 & 4531 & $80(41.9)$ & $433(9.6)$ & 5.4 \\
III & $31-40$ & 60 & 2015 & $28(46.7)$ & $188(9.3)^{\mathrm{B}}$ & 6.7 \\
IV & $\geq 41$ & 18 & 1140 & $12(66.6)$ & $64(5.6)^{\mathrm{C}}$ & 5.3 \\
\hline
\end{tabular}

${ }_{1}^{1}$ percentage of piglets relative to the number of transferred zygotes. Different superscripts ${ }^{A B, C}$ within a column indicate significant differences at $\mathrm{P}<0.01$

The data summarized in Table 4 indicates that the season of the year has an impact on the efficiency of transgenic pig production. The best efficiency was obtained in the autumn, as measured by the percentage of farrowed sows and the percentage of piglets born $(\mathrm{P}<0.01)$. A significant downward trend, measured by the mean/average number of piglets born per sow, was found in winter. The efficiency of piglet production from transformed zygotes obtained in spring and summer was comparable. 
Table 4. Results of transfer of DNA microinjected pig zygotes with different gene constructs relative to season of the year

\begin{tabular}{|c|c|c|c|c|c|c|}
\hline \multirow{3}{*}{$\begin{array}{l}\text { Season of } \\
\text { the year }\end{array}$} & \multirow{3}{*}{$\begin{array}{c}\text { Transferred } \\
\text { zygotes } \\
n\end{array}$} & \multirow{3}{*}{$\begin{array}{c}\text { Recipients } \\
n\end{array}$} & \multirow{3}{*}{$\begin{array}{l}\text { Pregnant } \\
\text { recipients } \\
\text { n } \%\end{array}$} & \multicolumn{3}{|c|}{ Piglets born ${ }^{1}$} \\
\hline & & & & \multicolumn{2}{|c|}{ live } & \multirow{2}{*}{$\frac{\text { stillborn }}{\mathrm{n}}$} \\
\hline & & & & $\mathrm{n}$ & $\%$ & \\
\hline Spring & 3037 & 103 & $39(37.8)$ & 233 & $(7.7)^{\mathrm{A}}$ & - \\
\hline Summer & 597 & 23 & $8(34.8)$ & 50 & $(8.4)$ & - \\
\hline Autumn & 2684 & 98 & $56(57.1)$ & 300 & $(11.2)^{\mathrm{B}}$ & 33 \\
\hline Winter & 1921 & 74 & $30(40.5)$ & 132 & (6.9) & 6 \\
\hline
\end{tabular}

${ }^{1}$ percentage of piglets relative to the number of transferred zygotes. Different superscripts ${ }^{\mathrm{A}, \mathrm{B}}$ within a column indicate significant differences at $\mathrm{P}<0.01$

\section{DISCUSSION}

Transgenic animal production is a complex process and its efficiency is influenced by many factors. It is difficult to determine which factors are the most important, they may be of a molecular origin or an embryological one. All these factors have key roles in a long chain of research that ends in the production of a transgenic individual. Since the chain commences with a gene which is used to introduce specific changes in the host genome, and we also expect that gene is involved at the end of the chain by producing the required protein, molecular factors play a critical role in the whole transgenic process. However, in the middle of the chain there are several links which are also expected to play a role, such as the methods used to produce a sufficient number of host zygotes, for example by culturing them. The method of DNA insertion into a host genome by DNA microinjection is also important. The processes used to transfer the transformed zygotes into foster mothers are also critical. Therefore, there are a number of embryological and physiological factors that may influence the efficiency of transgenesis. This paper is mainly focused on the analysis of data relating to embryological and physiological factors that have a key role in pig transgenesis. An analysis of the influence of the type of gene construct used for pig zygote transformation showed that the promoter type used in vector construction and also the gene type (its lengths and probably the type of modification it generate) influence on transgenic efficiency. However, it is worth mentioning that up until now we have only obtained transgenic individuals (including homozygous individuals) with confirmed integration and expression of the pCMV FUT II gene.

For a particular transgenic process, the choice of promoter type linked to the specific gene to be expressed is strongly related to the planned genotype modification (Jura and Jurkiewicz, 2006). The modification can be directed through sys- 
temic expression, e.g., modification of the immune system as a target, or it can be limited to specific organs which will secrete a specific protein, this latter process is known as target expression. These different types of transformation require the use of different types of promoter.

Inducing a modification that will result in systemic expression is more difficult than performing a modification targeted to a particular organ, especially when the method of DNA microinjection is employed to insert the new genetic information. The modification may take place at a random locus on any chromosome, and this may disrupt the function of genes important in further embryo development. The collected data (Table 1) demonstrates that the use of the strong viral promoter pCMV for zygote transformation decreases the percentage of pregnant sows and the percentage of piglets born when compared to experiments where the organspecific WAP promoter was used. The data presented confirms observations from other researchers who suggested that the promoter type and also the type of genetic modification influences early embryo mortality (Melo et al., 2007).

Transfer of the transformed zygotes is one of the most important steps in the production of potential transgenic pigs, and it has a considerable effect on the number of animals that can be obtained. Surgical procedures for transferring pig embryos have been available for several decades (Ducro-Stevernik et al., 2004). The pregnancy rate of surgical embryo transfer of non-transformed pig embryos averaged about $60 \%$ (Ducro-Stevernik et al., 2004). Employment of non-surgical methods increased the pregnancy rate, but resulted in a lower litter size (DucroStevernik et al., 2004). Moreover, non-surgical transfer was performed with use of blastocyst stage embryos which require an extra six to seven days of in vitro culture (Ducro-Stevernik et al., 2004). In the case of transformed zygotes, the sooner they are transferred into the recipient oviducts, the greater the chance that the zygotes weakened by microinjection will find proper conditions for further development. Use of a transfer method into both oviducts of the recipient prolongs interference with the sow's reproductive system, which may cause inflammation of the oviducts. Moreover, transformed zygotes remain much longer in the unfavourable environment of in vitro culture. Transfer into a single oviduct considerably shortened surgical treatment, improved the organization of the transfer, and considerably improved the efficiency. The use of the single oviduct transfer method doubled the percentage of pregnant sows and the percentage of potential transgenic piglets obtained (Table 2).

The results presented in Table 3 show that the number of zygotes used for transfer into the oviduct of recipient sows does not essentially affect pregnancy rate. The highest mean number of piglets obtained per recipient was observed when the number of transferred zygotes ranged from 31- 40 (Table 3, group III). In a single experiment, the number of good quality transferrable zygotes deter- 
mines the superovulation efficiency, which is the whole number of zygotes suitable for transformation obtained. It is known that the number of good quality porcine embryos decreases with an increasing dosage of gonadotropins (Schlieper and Holtz, 1986). However, the number of recipients suitable for transfer depends mostly on the quality of animals, which vary according to farm conditions and the season of the year. Transfer of over than 40 (Table 3, group IV) zygotes into one recipient does not improve efficiency, the mean number of piglets produced from one recipient was the same as when less than 20 zygotes was transferred (Table 3, group I). From our experience indicates that transfer ranged from 21-30 transformed zygotes into the single oviduct of recipient sow is optimum.

When breeding farm animals, the influence of the season of the year is a well recognized factor. Therefore, it would be better to produce potential transgenic pigs at a time when the environmental factors are optimal, but this is not always possible. Data collected from six years of research shows that the highest production of piglets can be obtained in autumn. A downward trend was observed during the spring and summer seasons towards the winter, when the lowest rate was noticed (Table 4).

\section{CONCLUSIONS}

The production of transgenic pigs is a complex process. It is difficult to ascertain which of factors quoted in the literature is the determining factor in the efficiency of transgenesis. Based on our experiences over six years of research, the type of promoter and the transfer method are the factors which have a large influence on transgenesis efficiency in pigs, when using standard DNA microinjection techniques. The number of transferred zygotes into a recipient influence on the piglets production. The season of the year during which research was performed had a noticeable effect.

\section{REFERENCES}

Ducro-Stevernik D.W.B., Peters C.G.W., Maters C.C., Hazeleger W., Merks J.W.M., 2004. Reproduction results and offspring performance after non-surgical embryo transfer in pigs. Theriogenology 62, 522-531

Holtz W., Schlieper B., 1991. Unsatisfactory results with the transfer of embryos from gilts superovulated with PMSG and HCG. Theriogenology 35, 1237-1249

Jura J., Jurkiewicz. J., 2006. Methods for the production of transgenic animals. Ann. Anim. Sci., Suppl.1, 29-38

Kruip Th.A.M., Den Daas J.H.G., 1997. In vitro produced and cloned embryos: effects on pregnancy, parturition and offspring. Theriogenology 47, 43-52 
Martinez E.A., Vazquez J.M ., Roca J., Cuello C., Gil M.A., Parrilla I., Vazquez J.L., 2005. An update on reproductive technologies with potential short-term application in pig production. Reprod. Domest. Anim. 40, 300-309

Melo E.O., Canavessi A.M.O., Franco M.M., Rumpf R., 2007. Animal transgenesis: state of the art and applications. J. Appl. Genet. 48, 47-61

Schleiper B., Holtz W., 1986. Transfer of pig embryos collected by laparotomy or slaughtered. Anim. Reprod. Sci. 46, 1212-1217

Smorag Z., Gajda B., Jura J., Skrzyszowska M., Pasieka J., 1999. Factors affecting the production of zygotes in superovulated pigs: A seven-years retrospective study. Ann. Anim. Sci. 26, 155-161

Williams B.L., Skarks A.E.T., Canseco R.S., Knight J.W., Johnson J.L., Velander W.H., Page R.L., Drohan W.N., Kornegaj E.T., Pearson R.E., Wilkins T.D., Gwazdauskas F.C., 1992. Evaluation of systems for collection of porcine zygotes for DNA microinjection and transfer. Theriogenology $38,501-511$ 